\title{
Lungekreft blant norske nikkelverksarbeidere: Nytt lys på en klassisk studie
}

\author{
Tom Kristian Grimsrud \\ Kreftregisteret, Montebello, 0310 Oslo \\ Telefon: 2245-1300 Telefaks: 2245-1370 e-post: tom.k.grimsrud@kreftregisteret.no
}

\begin{abstract}
SAMMENDRAG
I 1973 ble det påvist økt risiko for lunge- og nese-/bihulekreft blant norske nikkelverksarbeidere i en epidemiologisk undersøkelse fra Kreftregisteret. Analysene var basert på 48 lungekrefttilfeller, og man fant at risikoen var høyest i den gruppen som hadde lengst ansettelse i roste-, smelte- og elektrolyseavdelingene. Tilsvarende funn var tidligere gjort blant nikkelarbeidere $i$ andre land, og undersøkelsen vakte oppsikt fordi forhøyet risiko også ble funnet blant ansatte i elektrolysen. Senere analyser med spesifikke eksponeringsdata har vist at kreftfaren er nært knyttet til eksponering for vannløselige nikkelformer. Nye data er nå blitt samlet inn i forbindelse med en pasient-kontroll-undersøkelse basert på 213 tilfeller av lungekreft og 525 kontrollpersoner. På bakgrunn av opplysningene er relativ risiko regnet ut ved hjelp av regresjonsmodeller der følgende faktorer var inkludert: total varighet av ansettelse ved bedriften, eller varighet av ansettelse i ulike avdelinger, tidspunkt for førsteansettelse og røykevaner. Resultatene fra pasient-kontroll-analysen bekreftet funnene fra 1973 når disse ble regnet om til relativ risiko, og tydet på at konklusjonene fra den gang var valide selv om analysene var basert på færre arbeidstakere, kortere observasjonstid, en forenklet inndeling av arbeidstakerene i henhold til deres avdelingshistorikk, og manglende opplysninger om røykevanene.
\end{abstract}

\section{Grimsrud TK. Lung cancer among Norwegian nickel-refinery workers: Reappraisial of a classical study. Nor J Epidemiol 2001; 11 (2): 171-176.}

\section{ENGLISH SUMMARY}

In 1973, increased risk of cancer of the lung and nasal cavities was demonstrated among Norwegian nickel workers in a study from The Cancer Registry of Norway (Kreftregisteret). The analyses were based on 48 cases of lung cancer and the highest risk was found in workers with the longest employment in the electrolysis, roasting, and smelting departments. The study gave supportive evidence to epidemiological findings from other countries and was the first to identify an elevated risk in electrolysis workers. Evaluations based on specific exposure information have indicated a clear carcinogenic effect from water-soluble nickel compounds. New information has been collected for a case-control study including 213 cases of lung cancer and 525 controls. Regression models were used to estimate the effect of the following variables: duration of employment at the refinery as a whole, or in three different department groups (electrolysis, roasting and smelting, and maintenance), time of first employment at the refinery, and smoking. The results from the case-control analyses were in agreement with most of the relative rates derived from the 1973 paper, and indicated that the conclusions in the oldest study were valid despite a much lower number of study subjects, a shorter follow-up, a simple categorisation of employees according to work history, and an absence of data on smoking habits.

\section{INNLEDNING}

Pedersen, Høgetveit og Andersens artikkel fra 1973 om luftveiskreft blant norske nikkelverksarbeidere var resultatet av et samarbeid mellom den aktuelle bedrift og Kreftregisterets forskere (1). De funn som ble gjort, vakte berettiget oppsikt nasjonalt og internasjonalt. Undersøkelsen ga støtte til tilsvarende funn som var gjort i andre land, og forfatterne var de første til å påvise økt kreftfare blant elektrolysearbeidere, som hovedsakelig hadde vært utsatt for nikkel i form av vannløselige salter (i første rekke nikkelsulfat og nikkelklorid).

Forfatterne beklaget mangelen på opplysninger om arbeidstakernes røykevaner, men fant det lite sannsynlig at røykevanene kunne forklare den sterke overrisikoen for lungekreft. Senere er manglende justering for røyking flere ganger fremhevet som en kilde til usikkerhet $(2,3)$. Et annet svakt punkt var at studien ikke tok hensyn til at mange arbeidstakere faktisk hadde vært ansatt ved flere ulike avdelinger (4).

Etter den første publikasjonen har kreftforekomsten 
i kohorten vært oppdatert flere ganger. I artikler fra 1982 og 1996 ble de ansattes røykevaner tatt hensyn til $i$ en del av analysene $(5,6)$, men riktignok bare som en todelt variabel ("røyker" eller "aldri-røyker"). I den internasjonale nikkelarbeiderstudien fra 1990 (2) og i artikkelen fra 1996 (6) ble analysene utført med data fra en eksponeringsmatrise som anga eksponering for fire typer nikkelforbindelser. Resultatene fra alle disse studiene har bekreftet og utdypet hovedfunnene i den første artikkelen. Det er påvist en nær sammenheng mellom kreft og eksponering for vannløselige nikkelforbindelser $(2,6)$.

Analyser på bakgrunn av avdelingshistorikk har imidlertid ikke vært utført siden insidensrater ble beregnet i 1973 og 1982. Nylig er det samlet inn detaljerte opplysninger om røykevaner for lungekreftpasienter og kontrollpersoner i samme gruppe nikkelarbeidere. Dagens analyseverktøy åpner dessuten for beregning av risiko ved hjelp av multivariable modeller, og i det følgende vil disse mulighetene bli tatt i bruk for å belyse noen av de sentrale funn fra 1973 med en optimal korreksjon for røyking.

\section{E Pedersen, A Chr Hogetveit og Aa ANDERSEN 1973 - RESYMÉ}

\section{Materiale og metode}

I studien til Pedersen og medarbeidere (1) så man på kreftforekomst hos 1916 menn som hadde arbeidet 3 år eller mer ved nikkelverket, og som var ansatt første gang før 1961. Oppfølgingstiden var fra 1953 til 1971. Alle deltakerne i undersøkelsen ble klassifisert etter den avdeling, eller rettere den gruppe av avdelinger, hvor de hadde hatt den lengste tilknytning eller den betydeligste eksponering. De observerte tall for kreftforekomst i arbeidstakergruppene ble sammenliknet med det forventete antall tilfeller i henhold til nasjonale kjønns- og aldersspesifikke rater fordelt på (tilnærmet) 5-årige observasjonsperioder. Utregningene ble foretatt på datamaskinen (!) ved Universitetet i Oslo.

Produksjonen av nikkel og kopper, og senere også kobolt, har vært og er i hovedsak basert på svovelholdige malmkonsentrater. Frem til 1978 startet behandlingen med knusing etterfulgt av rosting, som innebærer avbrenning av svovel, og derved omdanning av metallsulfider til metalloksider. Et senere trinn var smelting i tradisjonelle Søderbergovner, der metalloksidene ble redusert med karbon til en blanding av metaller (legering). Av denne massen ble det støpt elektroder, som i det vesentlige besto av nikkel. Siste hovedtrinn i prosessen var elektrolysen, der metallene ble skilt fra hverandre på bakgrunn av sine ulike elektrokjemiske egenskaper. En rekke trinn med ekstraksjon, felling, filtrering og tørking var skutt inn mellom disse hovedtrinnene og for det meste knyttet til elektrolyseavdelingene.

\section{Resultater}

De sentrale resultatene som gjelder lungekreft, er presentert i tabell 1-3 med standardiserte insidensrater (SIR), i tabellene ført opp som forholdet mellom observert antall og forventet antall krefttilfeller $(\mathrm{O} / \mathrm{F})$. Noen strata fra originaltabellene er slått sammen. Det er dessuten føyd til 95\% konfidensintervaller (95\% KI) under antakelsen av en Poisson-fordeling, og tilnærmete anslag for relativ risiko basert på SIR-verdiene.

Tabell 1. Resultater gjengitt fra artikkelen til Pedersen og medarbeidere fra 1973 (1), tabell I: Forekomst av lungekreft og tilnærmet relativ risiko blant nikkelverksansatte etter avdelingstilknytning. De tre kolonnene lengst til høyre (O/F, 95\% KI og "Relativ risiko") er regnet ut på bakgrunn av data i originaltabellen.

\begin{tabular}{lcccccc}
\hline Arbeidstakerkategori & Antall menn & Observert $(\mathrm{O})$ & Forventet $(\mathrm{F})$ & $\mathrm{O} / \mathrm{F}$ & $95 \% \mathrm{KI}^{\mathrm{a}}$ & "Relativ risiko" \\
\hline Roste- og smelteavdelingene & 462 & 12 & 2,5 & 4,80 & $2,48-8,40$ & 3,24 \\
Elektrolyseavdelingene & 609 & 26 & 3,6 & 7,22 & $4,72-10,6$ & 4,88 \\
Andre spesifiserte avdelinger & 299 & 6 & 1,3 & 4,62 & $1,69-10,1$ & 3,12 \\
Annet og uspesifisert arbeid & 546 & 4 & 2,7 & 1,48 & $0,40-3,79$ & $1,0^{\mathrm{b}}$ \\
$\quad$ Totalt & 1916 & 48 & 10,1 & 4,75 & $3,50-6,31$ & \\
\hline
\end{tabular}

${ }^{\mathrm{a}} \mathrm{KI}=$ konfidensintervall; ${ }^{\mathrm{b}}$ referanseverdi

Tabell 2. Resultater gjengitt fra artikkelen til Pedersen og medarbeidere fra 1973 (1), tabell II: Forekomst av lungekreft og tilnærmet relativ risiko blant nikkelverksansatte etter periode for førsteansettelse. De tre kolonnene lengst til høyre (O/F, 95\% KI og "Relativ risiko") er regnet ut på bakgrunn av data i originaltabellen.

\begin{tabular}{lcccccc}
\hline Første ansettelse & Antall menn & Observert (O) & Forventet (F) & O/F & $95 \% \mathrm{KI}^{\mathrm{a}}$ & "Relativ risiko" \\
\hline $1910-1929$ & 106 & 10 & 0,96 & 10,4 & $5,00-19,2$ & 2,36 \\
$1930-1940$ & 282 & 11 & 2,4 & 4,51 & $2,25-8,07$ & 1,02 \\
$1945-1954$ & 1091 & 23 & 5,2 & 4,41 & $2,80-6,62$ & $1,00^{\mathrm{b}}$ \\
$1955-1960$ & 437 & 4 & 1,57 & 2,55 & $0,69-6,52$ & 0,58 \\
\hline
\end{tabular}

${ }^{\mathrm{a}} \mathrm{KI}=$ konfidensintervall; ${ }^{\mathrm{b}}$ referanseverdi 
Tabell 3. Resultater gjengitt fra artikkelen til Pedersen og medarbeidere fra 1973 (1), tabell III: Forekomst av lungekreft blant nikkelverksarbeidere i roste-, smelte- og elektrolyseavdelingene etter periode for førsteansettelse og varighet av ansettelse. De to kolonnene lengst til høyre (O/F og 95\% KI) er regnet ut på bakgrunn av data i originaltabellen.

\begin{tabular}{lcccccc}
\hline Første ansettelse & Antall år ansatt & Antall menn & Observert(O) & Forventet (F) & O/F & $95 \% \mathrm{KI}^{\mathrm{a}}$ \\
\hline $1910-1929$ & $3-14$ & 10 & 1 & 0,10 & 10,0 & $0,25-55,7$ \\
& $15+$ & 54 & 9 & 0,43 & 20,9 & $9,59-39,8$ \\
$1930-1940$ & $3-14$ & 101 & 6 & 0,93 & 6,45 & $2,37-14,1$ \\
& $15+$ & 45 & 3 & 0,36 & 8,33 & $1,72-24,3$ \\
Totalt & $3+$ & 210 & 19 & 1,82 & 10,4 & $6,28-16,3$ \\
\hline
\end{tabular}

${ }^{\mathrm{a}} \mathrm{KI}=$ konfidensintervall

Hovedresultatene skal kort oppsummeres. Den høyeste risiko for lungekreft ble funnet blant ansatte i elektrolyseavdelingene og i roste- og smelteavdelingene (tabell 1). For hele kohorten ble det påvist en forekomst som var mer enn 4 ganger økt i forhold til befolkningen ( $\mathrm{SIR}=4,75 ; 95 \% \mathrm{KI} 3,50-6,31$ ).

Det ble funnet høyere risiko for lungekreft knyttet til førstegangsansettelse i den første produksjonsperioden fra 1910 til 1929 sammenlignet med perioden 1930 til 1954 (tabell 2). Forekomsten var fortsatt forhøyet for dem som ble ansatt etter 1930, og man fikk inntrykk av en nedadgående trend, som imidlertid var svært usikker med bare 4 observerte tilfeller i den gruppen som var ansatt sist.

En økt risiko med økende varighet av ansettelse ble bare funnet for dem som var kategorisert som elektrolyse- eller roste- og smeltearbeidere og som var ansatt før 1940. Resultatene for denne gruppen er vist $\mathrm{i}$ tabell 3. Av det totale antall på 48 lungekrefttilfeller som studien omfattet, ble 38 (79\%) funnet blant roste-, smelte- og elektrolyseansatte, som utgjorde $55 \%$ av alle personer i studien. Forfatterne beklaget at de ikke hadde opplysninger om røykevanene til de ansatte, men de konkluderte med at røyking neppe kunne forklare den økte kreftforekomsten.

\section{EN PASIENT-KONTROLL-UNDERSØKELSE AV LUNGEKREFT BLANT NIKKELARBEIDERE}

Målet med den nye pasient-kontroll-undersøkelsen var i utgangspunktet å vurdere effekten av eksponering for ulike nikkelforbindelser med bedre korreksjon både for røykevaner og for annen kreftfremkallende yrkeseksponering. I det følgende skal vi imidlertid se på se på risiko $\mathrm{i}$ forhold til ansettelsestidspunkt, total varighet av ansettelse ved verket, ansettelse i ulike avdelingsgrupper og røykevaner.

\section{Materiale og metode}

Pasient-kontroll-unders $ø$ kelsen tok utgangspunkt i en gruppe på 5389 mannlige nikkelarbeidere med 1 år eller lengre sammenlagt ansettelse mellom $1910 \mathrm{og}$ 1994. Deltakerne var alle i live 1. januar 1953. Det ble identifisert 227 tilfeller av lungekreft, hvorav det for
213 (94\%) lyktes å samle inn opplysninger om røykevaner gjennom intervju med personen selv eller med pårørende. Til pasienter med diagnose stilt i 1970 eller senere ble det trukket 3 kontrollpersoner med fødselsdag inntil to år før eller etter pasientens. Kontrollpersonene skulle være i live og ikke ha hatt lungekreft på pasientens diagnosetidspunkt (incidence density sampling). For pasienter med diagnose stilt før 1970 ble det etter tilsvarende kriterier trukket kun 1 kontroll per pasient av ressursmessige årsaker. Tilstrekkelig med data ble samlet inn for 525 av de 559 kontrollpersoner som var aktuelle (94\%). Fordelingen av fødselsår, diagnoseår, alder ved diagnose og røykevaner er satt opp i tabell 4 a til d.

Tabell 4 a-c. Lungekreft blant nikkelverksansatte: Fordeling av pasientene i en pasient-kontroll-undersøkelse etter fødselsår, diagnoseår og alder ved diagnose.

a) Etter fødselsår

\begin{tabular}{lcc}
\hline Fødselsår & Antall pasienter & Prosent \\
\hline $1883-1899$ & 20 & $9 \%$ \\
$1900-1909$ & 43 & $20 \%$ \\
$1910-1919$ & 69 & $32 \%$ \\
$1920-1929$ & 57 & $27 \%$ \\
$1930-1946$ & 24 & $11 \%$ \\
\hline
\end{tabular}

b) Etter diagnoseår

\begin{tabular}{lcc}
\hline Diagnoseår & Antall pasienter & Prosent \\
\hline $1952-1959$ & 8 & $4 \%$ \\
$1960-1969$ & 32 & $15 \%$ \\
$1970-1979$ & 54 & $25 \%$ \\
$1980-1989$ & 75 & $35 \%$ \\
$1990-1995$ & 44 & $21 \%$ \\
\hline
\end{tabular}

c) Etter alder ved diagnose

\begin{tabular}{lcc}
\hline Alder ved diagnose & Antall pasienter & Prosent \\
\hline $41-49$ år & 20 & $9 \%$ \\
$50-59 "$ & 49 & $23 \%$ \\
$60-69 "$ & 82 & $38 \%$ \\
$70-89 "$ & 62 & $29 \%$ \\
\hline
\end{tabular}


Tabell 4 d. Røykevaner blant nikkelverksansatte fordelt på pasienter og kontroller, og risiko for lungekreft.

\begin{tabular}{|c|c|c|c|c|c|c|}
\hline \multirow[b]{2}{*}{ Røykevaner } & \multicolumn{2}{|c|}{ Pasienter } & \multicolumn{2}{|c|}{ Kontroller } & \multirow[b]{2}{*}{$\mathrm{OR}^{\mathrm{a}}$} & \multirow[b]{2}{*}{$95 \% \mathrm{KI}^{\mathrm{b}}$} \\
\hline & Antall & Prosent & Antall & Prosent & & \\
\hline Aldri røykt & 4 & $2 \%$ & 93 & $18 \%$ & $1,0^{\mathrm{c}}$ & \\
\hline Eksrøyker $^{\mathrm{d}}$ & 22 & $10 \%$ & 141 & $27 \%$ & 3,82 & $1,29-11,3$ \\
\hline \multicolumn{7}{|l|}{ Dagligrøyker } \\
\hline $1-10$ gram per dag & 49 & $23 \%$ & 106 & $20 \%$ & 11,7 & $3,97-34,4$ \\
\hline $11-20$ gram per dag & 96 & $45 \%$ & 146 & $28 \%$ & 17,7 & $6,11-51,1$ \\
\hline$>20$ gram per dag & 42 & $20 \%$ & 39 & $7 \%$ & 29,8 & $9,58-92,8$ \\
\hline
\end{tabular}

${ }^{\mathrm{a}} \mathrm{OR}=$ odds ratio, oddsforhold; ${ }^{\mathrm{b}} \mathrm{KI}=$ konfidensintervall; ${ }^{\mathrm{c}}$ referanseverdi; ${ }^{\mathrm{d}}$ eksrøyker siste 5 år eller mer

Bedriftens oversikt over ansettelser og skifte av avdelinger ble brukt til å beregne total ansettelsestid i tre hovedgrupper av avdelinger: 1) Roste- og smelteavdelingene; 2) elektrolyseavdelingene, som inkluderte nikkel-, kopper- og koboltelektrolyse, elektrolyttrens, og kopperluting (= kopperekstraksjon); og 3) vedlikeholdsavdelingene. Forut for analysen ble hver av disse kontinuerlige variablene kategorisert med et referansenivå svarende til ingen ansettelse i den aktuelle avdelingsgruppe eller tre grader av varighet delt inn etter kriterier som tilsvarte analysene fra 1973: 1) mer enn 0, men kortere enn 3 år; 2) minst 3 år, men mindre enn 15 år; og 3) 15 års ansettelse eller mer. Fra røykeopplysningene ble det regnet ut gjennomsnittlig tobakksforbruk gjennom hver persons karriére som dagligrøyker. Personer som hadde sluttet å røyke 5 år eller mer før pasientens diagnosedato, ble regnet som tidligere røykere (eksrøykere).

Relativ risiko for lungekreft i form av oddsforhold (odds ratio) ble beregnet ved hjelp av betinget logistisk regresjon (7) på en personlig datamaskin (PC) av vanlig type med programpakken Stata (8). Forklaringsvariabler var: 1) periode for første ansettelse ved nikkelverket; 2) total varighet av ansettelse ved nikkelverket, uavhengig av avdeling eller type arbeid; og 3) varighet av ansettelse innenfor de tre ovenfor nevnte avdelingsgrupper. For å justere for mulig skjevfordelte røykevaner ble røyking tatt inn i modellene som en femdelt variabel med kategoriene aldri-røyker, eksrøyker, og dagligrøyker med 3 nivåer av forbruk på 1 til 10, 11 til 20, eller mer enn 20 g tobakk per dag. Resultatene er presentert med og uten korreksjon for røyking for å synliggjøre graden av konfundering.

\section{Resultater}

Beregnet risiko etter røykevaner alene er gjengitt i tabell $4 \mathrm{~d}$. Risiko etter ansettelsesvarighet uansett avdeling viste en strengt monoton trend, med en signifikant dobling av risikoen ved ansettelse over 15 år (tabell 5). Risikoen var størst blant dem som ble ansatt i nikkelverkets første driftsperiode, med ubetydelig variasjon $\mathrm{i}$ de etterfølgende tiår (tabell 5).

Forhøyet risiko var forbundet med arbeid i alle hovedgruppene av avdelinger som inngikk $\mathrm{i}$ analysen (tabell 6), også etter justering for førsteansettelse før eller etter 1930 og for røykevaner. For arbeid i rosteog smelteavdelingene og for elektrolyseavdelingene var det en strengt monotont stigende dose-responskurve, med en maksimal tredoblet risiko for roste- og smelteavdelingene og firedobling for elektrolyseavdelingene. Arbeid med vedlikehold var tilsynelatende forbundet med økt risiko, men resultatene var ikke statistisk signifikante på 5-prosentsnivå, og det var ingen entydig sammenheng mellom risiko og varigheten av denne type arbeid. Det var ikke holdepunkter for interaksjon mellom periode for førsteansettelse og varighet av arbeid i produksjonsavdelingene (sistnevnte representert ved en enkelt kontinuerlig variabel; resultat ikke vist i tabell).

\section{SAMMENLIKNING OG DISKUSJON}

I de to studiene som er presentert i denne artikkelen, er det benyttet ulike mål for relativ risiko: tilnærmet relativ rate beregnet fra SIR-verdier, og oddsforhold (odds ratio) i pasient-kontroll-analysene. En korrekt sammenlikning av disse størrelsene ville i prinsippet kreve at en rekke formelle krav ble tilfredsstilt, men selv en noe grovere sammenlikning antas å være av interesse.

De to studiene fra henholdsvis 1973 og 2001 illusterer hver for seg og sammen et alvorlig problem med yrkesbetinget lungekreft blant nikkelarbeidere. Studiene skiller seg fra hverandre ved at den første benytter en ekstern sammenlikningsgruppe (nasjonale data) og angir kreftforekomsten i standardiserte insidensrater, mens den siste studien av type er en intern sammenlikning. Kravet for å være med i den første undersøkelsen var minimum 3 års ansettelsestid, mens kriteriet for den siste var 1 års ansettelse eller mer. Pasientkontroll-undersøkelsen omfattet mer enn 4 ganger så mange lungekrefttilfeller hovedsakelig på grunn av økt rekrutterings- og oppfølgingstid. Mens man i den første studien delte arbeidstakerne inn etter den avdeling som var antatt å ha størst betydning, åpnet pasientkontroll-studien for at samme arbeidstaker gjennom sin karriere kunne ha flere ulike avdelingstilknytninger. Videre ble detaljerte røykeopplysninger tatt inn i analysen. 
Tabell 5. Risiko for lungekreft blant nikkelverksansatte etter periode for første ansettelse og total varighet av ansettelse i en multivariabel analyse.

\begin{tabular}{|c|c|c|c|c|c|c|}
\hline & \multicolumn{2}{|c|}{ Antall } & \multicolumn{2}{|c|}{ Ukorrigert for røyking } & \multicolumn{2}{|c|}{ Korrigert for røyking } \\
\hline & Pasienter & Kontroller & $\mathrm{OR}^{\mathrm{a}}$ & $95 \% \mathrm{KI}^{\mathrm{b}}$ & $\mathrm{OR}^{\mathrm{a}}$ & $95 \% \mathrm{KI}^{\mathrm{b}}$ \\
\hline \multicolumn{7}{|l|}{ Første ansettelse } \\
\hline 1910-1929 & 18 & 18 & 1,95 & $0,85-4,45$ & 2,82 & $1,06-7,48$ \\
\hline 1930-1939 & 30 & 66 & 1,11 & $0,63-1,95$ & 1,01 & $0,54-1,89$ \\
\hline 1940-1949 & 41 & 106 & 0,91 & $0,57-1,44$ & 0,75 & $0,44-1,27$ \\
\hline $1950-1959$ & 86 & 210 & $1,0^{\mathrm{c}}$ & & $1,0^{\mathrm{c}}$ & \\
\hline 1960-1969 & 23 & 74 & 0,83 & $0,48-1,46$ & 1,09 & $0,59-2,01$ \\
\hline 1970-1978 & 13 & 47 & 0,80 & $0,40-1,57$ & 0,86 & $0,40-1,84$ \\
\hline 1979-1994 & 2 & 4 & 1,54 & $0,27-8,82$ & 1,72 & $0,21-14,0$ \\
\hline \multicolumn{7}{|l|}{ Varighet } \\
\hline $1-2,9$ år & 45 & 157 & $1,0^{\mathrm{c}}$ & & $1,0^{\mathrm{c}}$ & \\
\hline $3-14,9$ år & 73 & 178 & 1,38 & $0,89-2,15$ & 1,27 & $0,78-2,05$ \\
\hline 15 år + & 95 & 190 & 1,69 & $1,10-2,59$ & 2,00 & $1,24-3,24$ \\
\hline
\end{tabular}

${ }^{\mathrm{a}} \mathrm{OR}=$ odds ratio, oddsforhold; ${ }^{\mathrm{b}} \mathrm{KI}=$ konfidensintervall; ${ }^{\mathrm{c}}$ referanseverdi

Tabell 6. Risiko for lungekreft blant nikkelverksansatte etter periode for første ansettelse og varighet av ansettelse i elektrolyseavdelingene, roste- og smelteavdelingene og vedlikeholdsavdelingene (multivariabel analyse).

\begin{tabular}{|c|c|c|c|c|c|c|c|c|}
\hline \multirow[b]{2}{*}{ Arbeidshistorikk } & \multicolumn{2}{|c|}{ Varighet (år) } & \multicolumn{2}{|c|}{ Antall } & \multicolumn{2}{|c|}{ Ukorrigert for røyking } & \multicolumn{2}{|c|}{ Korrigert for røyking } \\
\hline & Definert & Gj.snitt $^{\mathrm{a}}$ & Pas. $^{\text {b }}$ & Kontr. $^{\mathrm{c}}$ & $\mathrm{OR}^{\mathrm{d}}$ & $95 \% \mathrm{KI}^{\mathrm{e}}$ & $\mathrm{OR}^{\mathrm{d}}$ & $95 \% \mathrm{KI}^{\mathrm{e}}$ \\
\hline \multicolumn{9}{|l|}{ Elektrolyseavdelingene } \\
\hline & 0 & 0 & 84 & 284 & $1,0^{\mathrm{f}}$ & & $1,0^{\mathrm{f}}$ & \\
\hline & $>0-2,9$ & 1,3 & 31 & 94 & 1,56 & $0,92-2,64$ & 1,93 & $1,08-3,47$ \\
\hline & $3-14,9$ & 8,1 & 50 & 83 & 2,72 & $1,66-4,46$ & 2,98 & $1,68-5,26$ \\
\hline & $15+$ & 25 & 48 & 64 & 3,59 & $2,11-6,10$ & 4,68 & $2,56-8,48$ \\
\hline \multicolumn{9}{|c|}{ Roste- og smelteavdelingene } \\
\hline & 0 & 0 & 125 & 335 & $1,0^{\mathrm{f}}$ & & $1,0^{\mathrm{f}}$ & \\
\hline & $>0-2,9$ & 1,4 & 37 & 89 & 1,44 & $0,89-2,35$ & 1,33 & $0,76-2,31$ \\
\hline & $3-14,9$ & 7,2 & 27 & 68 & 1,47 & $0,85-2,49$ & 1,50 & $0,83-2,74$ \\
\hline & $15+$ & 24 & 24 & 33 & 2,91 & $1,50-5,61$ & 3,36 & $1,59-7,08$ \\
\hline \multicolumn{9}{|c|}{ Vedlikeholdsavdelingene } \\
\hline & 0 & 0 & 162 & 382 & $1,0^{\mathrm{f}}$ & & $1,0^{\mathrm{f}}$ & \\
\hline & $>0-2,9$ & 1,6 & 17 & 50 & 1,49 & $0,78-2,84$ & 1,60 & $0,77-3,32$ \\
\hline & $3-14,9$ & 8,3 & 23 & 54 & 1,55 & $0,86-2,78$ & 1,52 & $0,79-2,94$ \\
\hline & $15+$ & 26 & 11 & 39 & 1,20 & $0,55-2,64$ & 1,09 & $0,44-2,73$ \\
\hline \multicolumn{9}{|l|}{ Første ansettelse } \\
\hline 1930 eller senere & & & 195 & 507 & $1,0^{\mathrm{f}}$ & & $1,0^{\mathrm{f}}$ & \\
\hline Før 1930 & & & 18 & 18 & 2,16 & $0,92-5,11$ & 3,20 & $1,26-8,12$ \\
\hline
\end{tabular}

${ }^{\mathrm{a}}$ gjennomsnitt for pasienter og kontroller innenfor hver kategori; ${ }^{\mathrm{b}}$ Pas. $=$ pasienter; ${ }^{\mathrm{c}}$ Kontr. $=$ kontroller;

${ }^{\mathrm{d}} \mathrm{OR}=$ odds ratio, oddsforhold; ${ }^{\mathrm{e}} \mathrm{KI}=$ konfidensintervall; ${ }^{\mathrm{f}}$ referanseverdi

De fleste av funnene $\mathrm{i}$ de to studiene viste god overensstemmelse. Risikoen blant ansatte som begynte ved bedriften før 1930 var mer enn fordoblet i forhold til senere ansatte, også etter justering for røykevaner og total ansettelsesvarighet. I tråd med funnene fra kohortoppdateringene fra 1982 og $1996(5,6)$ så risikoen ut til å holde seg forhøyet også blant personer som ble ansatt $i$ årene frem mot 1978.

Risikoen som Pedersen og medarbeidere påviste i de store produksjonsavdelingene kom tydelig frem også i pasient-kontroll-analysen, med økende risiko ved økende ansettelseslengde, selv etter gjensidig justering for arbeid ved de ulike avdelingsgruppene, for ansettelse før eller etter 1930, og for røykevaner. Det er verd å merke seg at risikoen faktisk var signifikant økt også etter arbeid i elektrolyseavdelingene i kortere tid enn 3 år, og at denne risikoen vanskelig kunne bli fanget opp i den eldste studien på grunn av inklusjonskriteriene og kategoriseringen.

Det store antall lungekrefttilfeller som etter hvert har oppstått, er ikke bare et resultat av kreftfare i arbeidsmiljøet. En økning i de nasjonale lungekreftrate- 
ne for menn har pågått gjennom hele den periode disse tilfellene er diagnostisert; fra 9,7 per 100000 personår i perioden 1953-1957, til 25,3 og 36,7 henholdsvis 20 og 40 år senere (1973-1977 og 1993-1997, aldersjusterte rater, verdens standardbefolkning, data fra Kreftregisteret). Bak økningen ligger i hovedsak utviklingen i røykevanene på 1900-tallet, der andelen dagligrøykere blant menn nådde et topp-punkt på 1950-tallet (9). Røykevanenes sentrale rolle illustreres også av risikogradienten i pasient-kontroll-materialet, risikotall som kjennes igjen fra tallrike prospektive studier av sammenhengen mellom røyking og lungekreft.

Anslagene for risiko knyttet til arbeidserfaring endret seg relativt lite når det ble korrigert for røyking i pasient-kontroll-analysene. Maksimal endring var på $48 \%$, mens gjennomsnittlig tallverdi av den prosentvise endring var $17 \%$ for de resultater som er vist $i$ tabell 5 og 6 . Alle de statistisk signifikante resultatene viste et avvik i samme retning fra referanseverdien enten det ble eller ikke ble korrigert for røyking. Dette er i tråd med tidligere erfaringer fra norske undersøkelser av yrkesbetinget lungekreft (10-12).

Som en konklusjon må det sies å være godt samsvar mellom resultatene i de to studiene. Validiteten av undersøkelsen fra 1973 synes tilfredsstillende til tross for at den var basert på færre pasienter, kortere oppfølgingstid, en forenklet inndeling av arbeidstakerne etter avdelingstilknytning, og manglende informasjon om deltakernes røykevaner.

Både undersøkelsen fra 1973 og pasient-kontroll-studien ble støttet av Den Norske Kreftforening. Den siste studien har tillegg vært finansiert med midler fra Arbeidsmiljøfondet til Næringslivets Hovedorganisasjon (NHO), Falconbridge Nikkelverk A/S og Kreftregisteret. Takk rettes til Aage Andersen, Tor Haldorsen og Steinar R Berge for viktige bidrag under arbeidet med pasient-kontroll-undersøkelsen.

\section{REFERANSER}

1. Pedersen E, Høgetveit AC, Andersen A. Cancer of respiratory organs among workers at a nickel refinery in Norway. Int J Cancer 1973; 12: 32-41.

2. Doll R, Andersen A, Cooper WC, Cosmatos I, Cragle DL, Easton D, et al. Report of the International Committee on Nickel Carcinogenesis in Man. Scand J Work Environ Health 1990; 16 (1, special issue): 1-82.

3. Haber LT, Erdreicht L, Diamond GL, Maier AM, Ratney R, Zhao Q, et al. Hazard identification and dose response of inhaled nickel-soluble salts. Regul Toxicol Pharmacol 2000; 31 (2 Pt 1): 210-30.

4. Doll R. Nickel exposure: A human health hazard. I: Sunderman FWj, Aitio A, Berlin A, Bishop C, Buringh E, Davis W, et al., editors. Nickel in the human environment, proceedings of a joint symposium held at IARC, Lyon, France, 8-11 March 1983. Lyon: IARC, 1984: 3-21.

5. Magnus K, Andersen A, Høgetveit AC. Cancer of respiratory organs among workers at a nickel refinery in Norway. Int J Cancer 1982; 30: 681-5.

6. Andersen A, Engeland A, Berge SR, Norseth T. Exposure to nickel compounds and smoking in relation to incidence of lung and nasal cancer among nickel refinery workers. Occup Environ Med 1996; 53: 708-13.

7. Breslow NE, Day NE. Statistical methods in cancer research, Volume 1 - The analysis of case-control studies. Lyon: IARC, 1980.

8. StataCorp. Stata Statistical Software: Release 7.0. College Station, TX: Stata Corporation, 2001.

9. Rønneberg A, Lund KE, Hafstad A. Lifetime smoking habits among Norwegian men and women born between 1890 and 1974. Int J Epidemiol 1994; 23 (2): 267-76.

10. Grimsrud TK. Arbeidsmiljø og røyking som årsak til lungekreft: noen epidemiologiske betraktninger (Occupational exposures and smoking as causes of lung cancer: Some epidemiological considerations). Nor $J$ Epidemiol 1995; 5 (2): 121-7.

11. Grimsrud TK, Langseth H, Engeland A, Andersen A. Lung and bladder cancer in a Norwegian municipality with iron and steel producing industry: population based case-control studies. Occup Environ Med 1998; 55: 387-92.

12. Romundstad P, Andersen A, Haldorsen T. Cancer incidence among workers in the Norwegian silicon carbide industry. Am J Epidemiol 2001; 153 (10): 978-86. 